\title{
Histopathology reporting in large bowel cancer
}

\author{
WK BLENKINSOPP, S STEWART-BROWN, L BLESOVSKY, G KEARNEY, \\ LP FIELDING
}

From the Department of Histopathology and the Academic Surgical Unit, St Mary's Hospital Medical School, London W2 IPG

SUMMARY A review of histopathology reports on 2046 patients in the large bowel cancer project showed considerable observer variation in histological grading, Dukes staging, and lymph node harvest. These parameters have a well-established relationship to prognosis, but, if they are to be applied for both clinical and research purposes, they must be assessed consistently. A minimal level of information which should be recorded from a resection specimen is suggested, with a description of the methods by which this information can be obtained.

The large bowel cancer project was initiated in 1976, and currently specimens are sent to the 22 histopathology departments from the 84 participating surgeons. Although many departments have more than one histopathologist to deal with these specimens, they have been treated as 22 observers for this analysis.

The objective of this part of the study was to assess the consistency of reports on the histopathology of the resected specimens. We anticipated that there might be considerable observer variation in histological grading, which is a subjective process, but we did not expect significant differences in the staging of local tumour spread, which is an objective assessment with sharp delineation between subgroups, or in lymph node harvest. We report here the results on 2046 resected tumours. We found clinically important and statistically significant differences between histopathology departments in the reporting of these specimens. Differences between hospitals have been calculated using the $\chi^{2}$ test for independent samples.

\section{Histological grading}

Dukes and Bussey ${ }^{1}$ classified 2097 rectal cancers into three histological grades and found that $19 \%$ were well differentiated, $60 \%$ moderately, and $20 \%$ poorly. The age-corrected five-year survival figures were $77 \%, 61 \%$, and $29 \%$ in order of decreasing differentiation.

In the present study of 2046 specimens $26 \%$ were well, $58 \%$ moderately, and $16 \%$ poorly differentiated; however, the proportion placed in each grade by the different observers varied widely: well-differentiated $3-93 \%$, moderately $8-82 \%$, and poorly $5-30 \%$

Accepted for publication 30 September 1980
(Fig. 1). The difference between observers was statistically significant $(P<0.001)$. Some lack of uniformity is inevitable in grading, but the order of difference shown can be due only to different techniques of assessment.
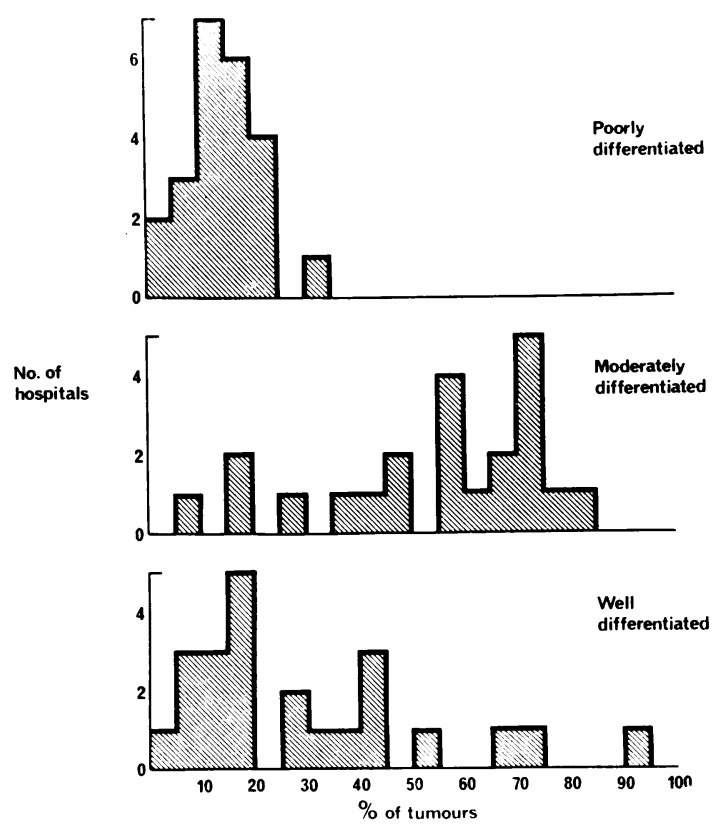

Fig. 1 Observer variation in assessment of tumour differentiation. The histogram describes the numbers of hospitals with their percentage of tumours in each category. For poorly-differentiated tumours there is grouping around the mean value but for the other two categories there is wide dispersion of results. 


\section{Dukes staging}

Dukes and Bussey ${ }^{1}$ reported the staging of 2037 cases: $15 \%$ were A (not through muscularis propria and no lymph node metastasis), 34\% B (through muscularis propria but no node metastasis), and $51 \%$ $\mathrm{C}$ (node metastasis). Recently, Talbot et al. $^{2}$ found very similar proportions in 702 rectal cancers: $14 \% \mathrm{~A}$, $38 \% \mathrm{~B}$, and $49 \% \mathrm{C}$. The age-corrected five-year survival figures in the two series are also very similar, respectively, $98 \%$ and $96 \%$ for stage $A, 78 \%$ and $78 \%$ for stage $B$, and $32 \%$ and $31 \%$ for stage $C$.

The Dukes staging links two factors-depth of local penetration and lymph node metastasis. These are known to be related but to some extent are independent. Dukes and Bussey ${ }^{1}$ found node metastasis in $14 \%$ of 402 rectal cancers not extending beyond the muscularis, whereas $60 \%$ of 1430 cases with extension beyond the muscularis propria had node metastasis. Grinnell and Lane $^{3}$ found node metastasis in $10 \%$ of carcinomas extending into but not through the muscularis, and in $12 \%$ of carcinomas extending only into the submucosa. Because lymph node metastasis is to some extent independent of depth of penetration these two variables have been analysed separately in the present study.

\section{Depth of penetration}

The figures of Dukes and Bussey ${ }^{1}$ show that $17 \%$ of carcinomas extended into but not through muscle, and $83 \%$ extended through muscle, including specimens with and without node metastasis. In the present study of 2046 cases, $13 \%$ did not extend through muscle, but again observer variation was considerable: $5 \%$ to $30 \%$ (Fig. 2) and these differences were statistically significant $(P<0.001)$. It is unlikely that this variation can be attributed to different methods of case selection, and since the microscopic appearances are seldom difficult to interpret errors probably lie in the macroscopic assessment.

\section{Lymph node harvest}

The influence of lymph node metastasis on prognosis is well known, and the relationship applies to both site and number of nodes involved. Dukes and Bussey ${ }^{1}$ found that of 1037 cases with node metastasis $29 \%$ had involvement of the nodes at the point of ligature of the blood vessels (stage C2), and these patients had an age-corrected five-year survival of $14 \%$, whereas $71 \%$ had no involvement of these nodes (stage C1) and these had a five-year survival of $41 \%$. Furthermore, the number of nodes with tumour deposits influenced prognosis: $22 \%$ of 564

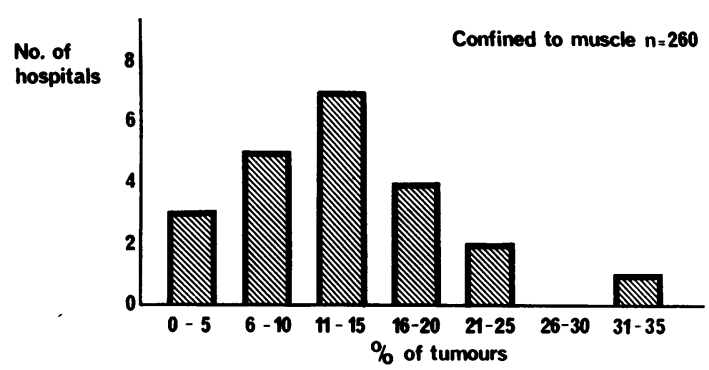

Fig. 2 Observer variation in assessment of extent of local spread. The histogram demonstrates the numbers of hospitals with their percentage of tumours confined to muscle.

cases had 1 node metastasis, $44 \%$ had $2-5,24 \%$ had ir $6-10$, and $9 \%$ had more than 10 ; the age-corrected five-year survival was respectively $64 \%, 36 \%, 22 \%$, 음 and $2 \%$. Talbot et al. ${ }^{2}$ found an age-corrected five- year survival of $43 \%$ for 181 cases with 1-3 nodes 3 involved, compared with $17 \%$ of 147 cases with or more nodes involved.

The validity of this assessment depends on the total number of lymph nodes found, and in the present study the overall mean value for lymph nodeo harvest was $5 \cdot 25 \pm 4 \cdot 7$ SD per specimen. However, comparison of the mean value for each hospitalo showed a wide range, $1.0 \pm 1.6 \mathrm{SD}$ to $11 \cdot 2 \pm 5 \cdot 8 \mathrm{SD}$ 응 (Fig. 3). These differences were statistically significant $(P<0.001)$ on analysis of variance.

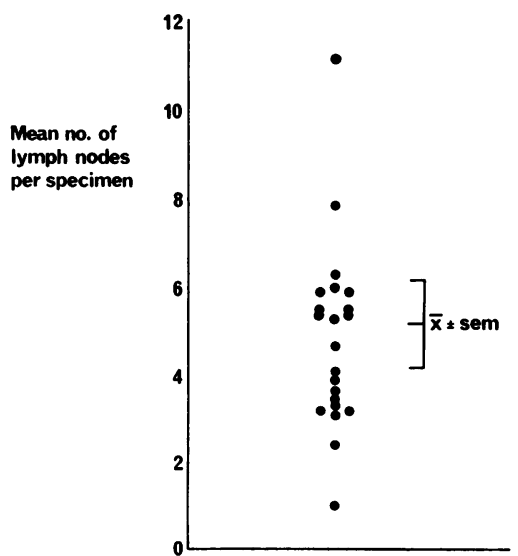

Fig. 3 Scattergram of the mean value of numbers of lymph nodes per specimen in each hospital. This diagram does not include those specimens in which nodal status was recorded but the number of lymph nodes examined was not specified, which accounted for $12.7 \%$ of specimens.

Similarly, the proportion of specimens in which lymph nodes were not found varied between hospitals (Fig. 4). 


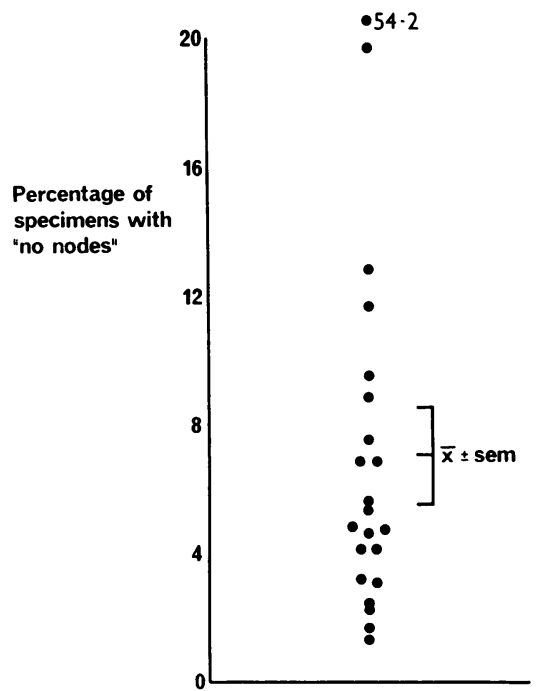

Fig. 4 Scattergram of the percentage of specimens in which lymph nodes were not found in each hospital.

\section{The report on a resected large bowel cancer}

From the results of this survey and our experience of various reporting techniques we suggest that the following system provides a basic level of information which should be reported on a resection specimen of large bowel cancer. The size of the tumour and the distance from each end of the specimen are measured. The presence of polyps or other pathology is noted. Serosal involvement is sought. The depth of invasion is assessed by a slice through the bowel wall at the site of maximum penetration, and a block (A) from this site is taken for microscopy. One or more longitudinal blocks (B) are taken of the margin if this is less than $1 \mathrm{~cm}$. The attached mesentery or posterior fat is dissected off the muscular wall of the bowel, laid flat, and cut into $3-5 \mathrm{~mm}$ slices; half of each lymph node found is taken for microscopy, and the node (block C) nearest the ligature on the vascular pedicle is kept separate from the remainder (block/s D).

The microscopy indicates the depth of invasion, whether resection is complete or not (in the long axis and radially), the presence or absence of serosal involvement, the lymph node score (number positive/ total), and the Dukes staging (A, B, C,). If possible, C cases are divided into $\mathrm{Cl}$ (proximal node negative) and $\mathrm{C} 2$ (proximal node positive). If other organs are adherent, a block is taken through the attachment to establish whether the adhesion is inflammatory or carcinomatous.

The grade of differentiation is assessed from the least differentiated area. Solid masses of malignant cells with spaces containing mucin but no recognisable glands characterise poorly-differentiated carcinoma (Fig. 5). Well-differentiated carcinomas (Fig. 6) consist entirely of glands, with cells showing nuclear polarity and not more than two layers deep. All other adenocarcinomas are classified as moderately-differentiated (Fig. 7). Small solid foci attributable to tangential sections through glands and multilayering due to the same cause are ignored. Mucinous (colloid) carcinomas can be separated into the same three categories. Carcinoids and the rare signet-ring cell, undifferentiated, and squamous carcinomas are classified separately.

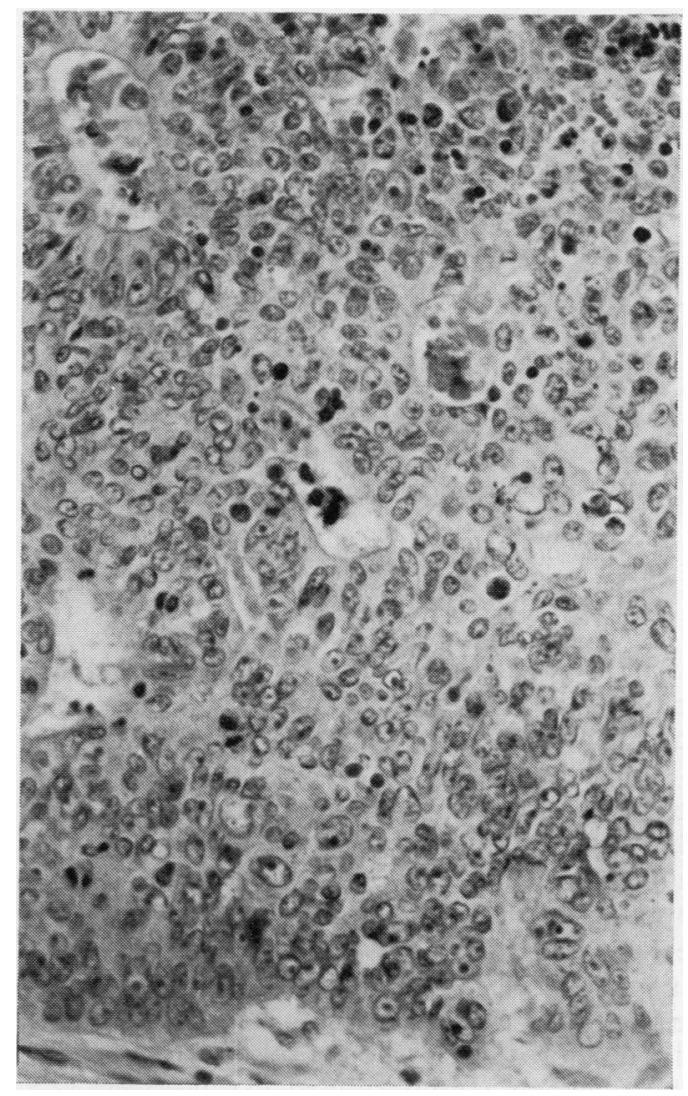

Fig. 5 Poorly-differentiated adenocarcinoma. ( $H$ and $E \times 300$ ).

We use a simple form set out as a check-list to assist in the reporting of these specimens, and copies are available from LPF.

\section{Discussion}

Precise information on resected specimens of large 


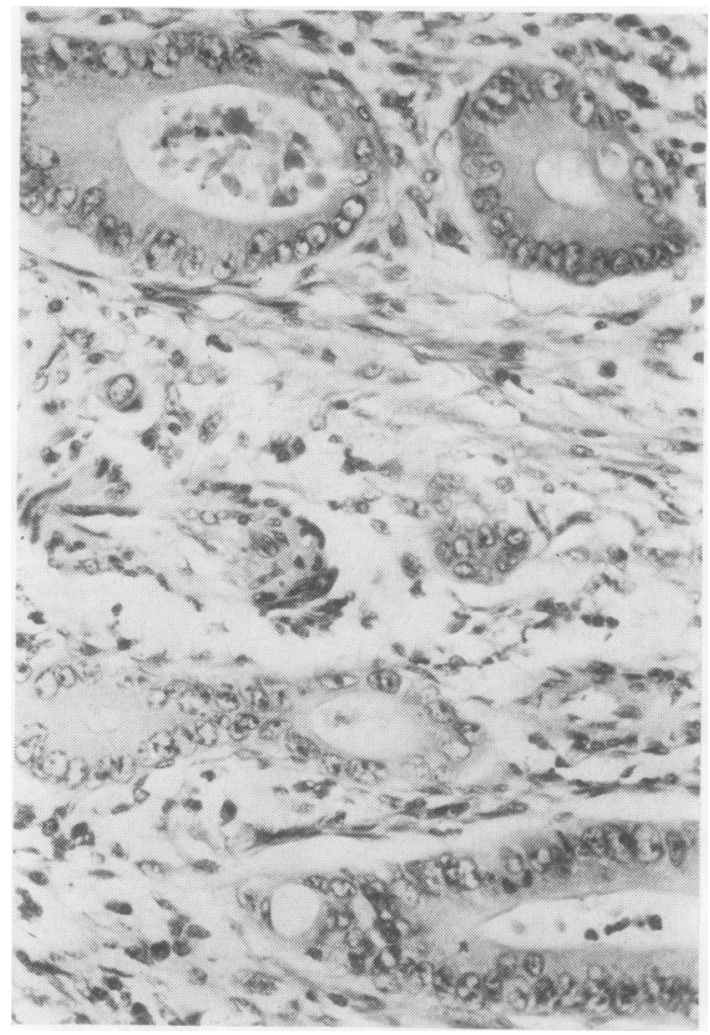

Fig. 6 Well-differentiated adenocarcinoma. ( $H$ and $E \times 300$ ).

gut cancer is necessary for prognosis and management and is crucial to prospective comparative studies. The present investigation shows that this is not consistently achieved in the relatively simple assessment of this common tumour.

Survival figures and prognostic features are best documented for rectal cancer, but similar trends apply to carcinoma elsewhere in the large gut. Shepherd and Jones ${ }^{4}$ found an age-corrected fiveyear survival of $57 \%$ for 341 rectal carcinomas after resection, $67 \%$ for 191 carcinomas of the left colon, and $51 \%$ for 124 carcinomas of the right colon. Dukes C cases as a proportion of all stages were $37 \%$ $22 \%$, and $32 \%$ respectively.

Buckwalter and $\mathrm{Kent}^{5}$ reviewed published work relating margin to local recurrence and survival and suggested that $5 \mathrm{~cm}$ was an adequate margin. However, there have been improvements in operative techique since these studies in the 1960s, and general experience now is that local recurrence is far less frequent despite smaller margins and that only a margin of $1 \mathrm{~cm}$ or less would now give rise to concern and histological investigation. ${ }^{6}$ In our view, longitudi-

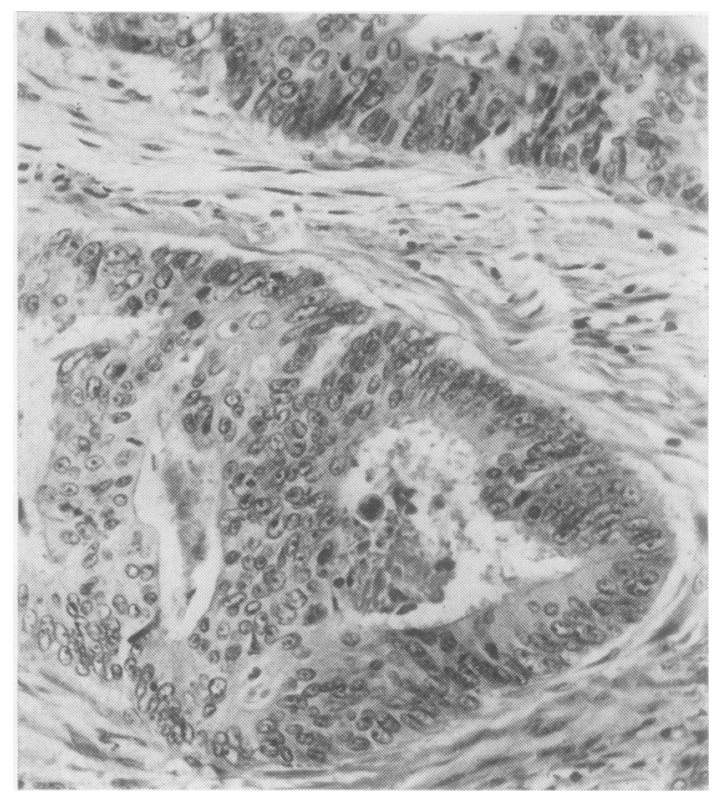

Fig. 7 Moderately-differentiated adenocarcinoma.

( $H$ and $E \times 300)$.

nal blocks through the minimum margin if this is $1 \mathrm{~cm}$ or less provide a satisfactory answer, but we are $\mathbb{\Phi}$ aware that other pathologists prefer circumferential $\stackrel{\varrho}{\Rightarrow}$ blocks of the margins. Small margins are often 윽 associated with circular stapling devices used in anterior resection; the "doughnuts" of bowel wall removed with this procedure should also be examined microscopically if the margin is less than $1 \mathrm{~cm}$.

Serosal involvement appears to be associated with a poor survival-less than $10 \%$ survival at five years was reported by Dukes and Bussey 1 -but this is less $\delta$ well documented than penetration through muscle.

Talbot et $a .^{2}$ have recently provided a detailed $ᄋ$ analysis of the occurrence and significance of venous $>$ invasion in rectal cancer. Extramural venous invasion was found to be of major prognostic significance: $N$ it was present in $36 \%$ of cases and was associated with a reduction in corrected five-year survival from $N$ $71 \%$ to $33 \%$. Involvement of thick-walled extra- $\underset{\omega}{\omega}$ mural veins (in $13 \%$ of cases) reduced the survival to $19 \%$. Unfortunately, this assessment required 0 multiple tangential blocks at the periphery of the $\frac{\Phi}{\Phi}$ tumour-the detection rate could be reproduced to $\stackrel{?}{?}$ within $4 \%$ by 5 blocks, $11 \%$ by 4 blocks, $23 \%$ by 3 ㄲ blocks, and $41 \%$ by 2 blocks. ${ }^{7}$ It is likely, therefore,

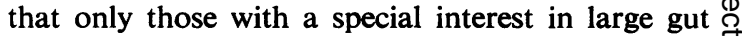
cancer will be able to provide this useful information. $\stackrel{\mathbb{Q}}{\Omega}$

Large gut cancer is sufficiently common that for a relatively small effort consistent and reliable reports should be easily obtained. It is highly desirable that 
histopathologists achieve this for the management of individual patients, and for clinical trials it is essential.

We gratefully acknowledge the histopathologists and surgeons listed below who took part in this study. We also wish to express our thanks to Dr Basil Morson, Dr Gerard Slavin, and Mr Ian Todd, who took part in an informal discussion of the data before publication. We owe grateful thanks to Downs Surgical Ltd, the Mrs Jessy Willmot bequest, the locally organised research scheme of the North West Thames Regional Health Authority, and the Cancer Research Campaign for generous financial support.

\section{Participants in the large bowel cancer project}

DW Blair, AJ Carr, AI Davidson, J Engesett, SB Ewen, PR Jones, J Kyle, NA Matheson, SS Miller, G Smith (Aberdeen Royal Infirmary). N Baker, OD Morris, WC Richards (Ashford General Hospital). AA Gunn, DAD Macleod, G Sclare (Bangour General Hospital). WA Anderson, K Callum, J Cocker, T Farnon, P Goodall, G Harrison, SG Hollander, DR Thomas (Derbyshire Royal Infirmary). JWP Bradley, TJC Cooke, AT Davey, DDO Lavertine, JV Piper, JEL Sales, CG Scorer, B Shorey (Hillingdon Hospital). J Chamberlain, M Lesner, AH Petty, BE Tomlinson, CW Venables, RG Wilson (Newcastle General Hospital). HB Devlin, RG Lawler, A Peel, EW Walton (North Tees General Hospital). AG Cox, A Elton, AE Kark, J Lewis, D Pinto, A Price, G Slavin (Northwick Park Hospital). A Davidson, A Price (Perth Royal Infirmary). GL Bohn, D Goodwin, F Hampson, CS Kirkham, C Latto, M Ross, G Rothnie (Royal Berkshire Hospital and Battle Hospital, Reading). RH Grace, K Scott, S Ward (Royal Hospital, Wolverhampton). A Chant, J Fraser, S Karran, J Webster (Royal South Hants Hospital). PH Dickinson, LB Fleming, IDA Johnston, IF McNeil, R Taylor, A Watson, P Wright (Royal Victoria Infirmary, Newcastle upon Tyne). AS Chilvers, JM Edwards, BP Flannery, T Goodlier, AG Nash, BW Wells (St Helier Hospital). PR Hawley, HE Lockhart-Mummery, CV Mann, B Morson, A Parks, J Ritchie, J Thomson, I Todd (St Mark's Hospital). WK Blenkinsopp, HAF Dudley, HHG Eastcott, LP Fielding, G Glazer, JR Kenyon, MJ Kershaw,
S Wilson (St Mary's Hospitals). IG Froome, A Jackson, AV Pollock (Scarborough Hospital). S Desai, M Horwich, C Maddox, AL Oscier, HGH Richards, E Milford Ward (Scunthorpe General Hospital). P Isaacson, J Jenkins, FP McGinn, R Rowntree, CJ Smart, DH Wright (Southampton General Hospital). P Cassell, R Ramsay, FET Scott, EJ Williams (Wexham Park Hospital). D Cairns, JL Grogono, W Halley, B Higgs, PH Lord, JJ Lucey (Wycombe and Amersham General Hospitals).

\section{References}

${ }^{1}$ Dukes CE, Bussey HJR The spread of rectal cancer and its effect on prognosis. Br J Cancer 1958;12:309-20.

${ }^{2}$ Talbot IC, Ritchie S, Leighton $\mathrm{MH}$, Hughes AO, Bussey HJR, Morson BC. The clinical significance of invasion of veins by rectal cancer. Br J Surg 1980;67:43942.

${ }^{3}$ Grinnell RS, Lane N. Benign and malignant adenomatous polyps and papillary adenomas of the colon and rectum. An analysis of 1,856 tumours in 1,335 patients. Int Ahstr Surg 1958;106:519-38.

${ }^{4}$ Shepherd JM, Jones JFP. Adenocarcinoma of the large bowel. Br J Cancer 1971;25:680-90.

${ }^{5}$ Buckwalter JA, Kent TH. Prognosis and surgical pathology of carcinoma of the colon. Surg Gynecol Obstet 1973;136: 465-72.

${ }^{6}$ Morson BC. Personal communication 1980.

${ }^{7}$ Talbot IC. Personal communication 1980.

\section{Addendum}

During the past two years there has been feed-back of the results to the surgeons and pathologists involved, and comparison of the most recent data with those in this paper suggests an improvement in the standard of reporting. The proportion of tumours recently classified as well-differentiated ranged from $4-36 \%$, compared with $4-90 \%$ in the whole series, and for moderate differentiation 48$83 \%$ instead of $2-90 \%$. The mean lymph node harvest per specimen increased from $5 \cdot 3$ to $7 \cdot 0$, and comment on vascular invasion increased from $28 \%$ to $37 \%$ of specimens.

Requests for reprints to: $\mathrm{Mr}$ LP Fielding, Academic Surgical Unit, St Mary's Hospital Medical School, London W2 1PG, England. 